\title{
BMJ Open Predicting postoperative fatigue in surgically treated lung cancer patients in Norway: a longitudinal 5-month follow- up study
}

Therese Hugoy, ${ }^{1,2}$ Anners Lerdal (D) , 3,4 Tone Rustoen, ${ }^{5,6}$ Trine Oksholm ${ }^{7}$

To cite: Hugoy T, Lerdal A, Rustoen T, et al. Predicting postoperative fatigue in surgically treated lung cancer patients in Norway: a longitudinal 5-month follow-up study. BMJ Open 2019;9:e028192. doi:10.1136/ bmjopen-2018-028192

- Prepublication history for this paper is available online. To view these files, please visit the journal online (http://dx.doi. org/10.1136/bmjopen-2018028192).

Received 26 November 2018 Revised 26 August 2019 Accepted 03 September 2019

Check for updates

(c) Author(s) (or their employer(s)) 2019. Re-use permitted under CC BY-NC. No commercial re-use. See rights and permissions. Published by BMJ.

For numbered affiliations see end of article.

Correspondence to

Dr Trine Oksholm;

trine.oksholm@vid.no

\section{ABSTRACT}

Objectives Despite the negative influence of fatigue on quality of life in patients who undergo lung cancer surgery, little is known about the possible predictors of postoperative fatigue. The aim of this study was to examine demographic and clinical characteristics that might predict postoperative fatigue 5 months after lung cancer surgery.

Design A prospective longitudinal follow-up study comprising preoperative and postoperative questionnaires, including Lee Fatigue Scale, and sociodemographic and clinical data.

Setting Three university hospitals in Norway (eg, Oslo University Hospital, St. Olav University Hospital and Haukeland University Hospital).

Participants In total, 196 surgically treated patients who answered the questionnaires both preoperatively and at 5-month follow-up with valid fatigue scores.

Results Bivariate analyses showed that preoperative fatigue was associated with comorbidities and the symptoms of shortness of breath, cough, depression, anxiety, sleep disturbance and pain. Only cough was directly associated with preoperative fatigue in a regression model. Comorbidities and the symptoms of shortness of breath, cough, depression and sleep disturbance were associated with postoperative fatigue in the bivariate analyses, but only shortness of breath was associated with postoperative fatigue in the regression model. We did not find any significant correlations between fatigue and any treatment variable.

Conclusion Clinicians should pay special attention to lung symptoms and be aware that these may lead to long-term postoperative fatigue. Further research should examine whether interventions reducing lung symptoms, such as shortness of breath and coughing, may prevent development of fatigue in patients undergoing lung cancer surgery.

\section{INTRODUCTION}

Lung cancer (LC) is presently one of the most common malignancies, and it is estimated that $20 \%$ of cancer-related deaths are caused by LC. ${ }^{1}$ Only $20 \%$ of patients diagnosed with non-small cell lung cancer meet the criteria for surgery due to their late stage at diagnosis; for these patients, surgery may be curative. ${ }^{2}$
Strengths and limitations of this study

- Fatigue is a symptom that has a great impact on patients' quality of life, and this topic is relevant both to patients and healthcare providers.

- A large sample of surgically treated patients with lung cancer were included in the study; patients' fatigue was measured both preoperatively and after surgery. This gives information about fatigue after lung cancer surgery.

- There was a 5-month gap between the two measurement points. During this time, other factors might have influenced patients' fatigue experience.

- There were limited information on symptom management interventions such as physiotherapy and rehabilitation

In Norway during 2014, 5-year LC survival was generally $19 \%$ in women and $13 \%$ in men. ${ }^{1}$ In surgically treated patients, the 5-year survival ranges from $50 \%$ to $70 \%$, depending on the tumour stage at surgery.

Fatigue is common among cancer patients. An estimated $75 \%-90 \%$ of patients with LC report fatigue after cancer treatment. ${ }^{3}{ }^{4}$ Fatigue has been described as a complex, multidimensional symptom and has been defined as a sense of exhaustion, lack of energy or tiredness distinct from sleepiness, sadness or weakness. ${ }^{5}$ Cancer-related fatigue is related to cancer or its treatment and interferes with usual functioning. ${ }^{3}$ Fatigue has a negative impact on patients' health-related quality of life (HRQOL), ${ }^{6}$ their ability to receive treatment and their longterm prognosis. Although there are limited data on LC and fatigue in patients who have undergone surgery, it has been shown that fatigue has a negative impact on HRQOL in LC survivors. ${ }^{7}$ One study showed that fatigue was a significant predictor of survival at each time point assessed. ${ }^{8}$ In another study on symptom severity after thoracotomy, fatigue 
was reported as the most common and severe symptom at every time point. ${ }^{7}$

Several studies have reported interrelations between fatigue, cough and dyspnoea. ${ }^{8-11}$ Fatigue is also strongly related to symptoms of depression and anxiety. ${ }^{12}{ }^{13}$ Associations between fatigue and sex, pain, insomnia and dyspnoea have also been reported. ${ }^{12}{ }^{14}$ Studies on fatigue in populations with LC in different stages have also shown strong correlations between fatigue and sleep disturbance. ${ }^{6-15}$ Sarna et al, ${ }^{12}$ found that symptom severity in surgical patients was related to the extent of their comorbid condition. Other studies of patients with LC have also shown correlations between comorbidities and fatigue, ${ }^{6}$ as well as strong correlations between pulmonary diseases such as Chronic obstructive pulmonary disease (COPD) and asthma and fatigue. ${ }^{318}$ Studies of fatigue in the general population has shown a higher proportion of severe fatigue cases among women than among men. ${ }^{19} 20$ Thus, examining differences in fatigue in relation to sex among patients with LC is of interest. Fatigue has a negative impact on both patients with LC and survivors in general $^{21}$; however, to our knowledge, there have been no studies to date specifically investigating fatigue in surgically treated patients with LC.

Thus, our aim was to examine the relationships between fatigue and disease characteristics, treatment and other symptoms. We hypothesised that fatigue levels at 5-month follow-up would be significantly related to: (1) sex, (2) clinical variables (preoperative comorbidities, forced expiratory volume in $1 \mathrm{~s}\left(\mathrm{FEV}_{1}\right)$ and forced vital capacity (FVC)); (3) preoperative symptoms (shortness of breath, coughing, depression, anxiety, pain and sleep disturbance); and (4) treatment and medical variables (surgery type, cancer stage and adjuvant therapy).

\section{MATERIAL AND METHODS}

This study is part of a larger, longitudinal investigation of symptoms in patients with LC who were eligible for surgery, ${ }^{22-24}$ for which data were collected prior to surgery and prospectively at four time points up to 1 year after surgery. Here, we analysed the data collected prior to surgery and at the 5-month follow-up to gain insight into patients' experiences with fatigue before surgery and after the immediate postoperative period.

\section{Patients and settings}

Patients were included if they were 18 years or older, scheduled for primary LC surgery and could understand, read and write Norwegian. Patients with a benign or metastatic disease, whose surgery was cancelled or who had cognitive impairment were excluded. We recruited patients from three university hospitals in Norway: Oslo University Hospital, St. Olav University Hospital and Haukeland University Hospital. The recruitment started in November 2010 and was completed in March 2012.

\section{Patient and public involvement}

The study was founded Norwegian Cancer Society. The study was discussed with representatives from the Lung
Cancer subgroup before the study started and an article about the main result from the study is published in the membership journal for patients with LC.

\section{Study procedures}

Hospital research staff approached patients and explained the study purpose: $91 \%$ of the participants were recruited in the hospital 1-3 days before surgery, and the remainder in outpatient clinics prior to surgery. Patients signed a written informed consent before they completed several self-report questionnaires with information on sociodemographic and clinical characteristics, and symptoms both prior to surgery and at a 5-month follow-up. Permission to use the questionnaire was obtained from the copyright detectors before study start. Data on type of tumour, cancer stage, surgery type and lung function were collected from the patients' medical records. $\mathrm{FEV}_{1}$ and FVC were measured preoperatively using a spirometer. Five months after surgery, patients received questionnaires by regular mail, along with a postage-paid return envelope.

\section{Instruments and assessment}

Sociodemographic, clinical, symptom and fatigue characteristics

Patients provided information on their sex, marital status, living situation, level of education and employment status. Information on age, smoking status, $\mathrm{FEV}_{1}$, tumour histology, cancer stage, type of surgery, preoperative and postoperative treatment, postoperative complications and TNM classification were collected from patients' medical records; the TNM classification is a system for cancer staging based on tumour $(\mathrm{T})$, node $(\mathrm{N})$ and metastasis (M).

\section{Comorbidities}

Comorbidities were measured using the Self-administered Comorbidity Questionnaire-19 (SCQ-19), ${ }^{25}$ on which scores can range from 0 to 57 , with a higher score indicating a more severe comorbidity profile. The SCQ includes 16 comorbidities and 3 optional conditions. Patients indicated whether they had the comorbid condition (yes/no); if they had the condition they were asked if they received treatment for it; and finally if it limited their activities. The SCQ-19 has well-established validity and reliability and has been used to assess comorbidity in Norwegian oncology patients. ${ }^{25}$ Only the number of comorbidities was used in the present study.

\section{Fatigue}

The Lee Fatigue Scale (LFS) ${ }^{5}$ was used to measure fatigue at baseline and 5-month follow-up. The LFS consists of 18 items designed to assess fatigue (13 items) and energy (5 items). We used only the 13 fatigue items in this study. Patients were asked to rate each item on a $0-10$ scale, with a higher score indicating greater fatigue severity. A fatigue score was calculated using the mean of the 13 items at each measurement. The LFS has well-established validity and reliability. ${ }^{26} 27$ Fatigue scores at baseline were 
defined as preoperative fatigue and at 5-month follow-up as postoperative fatigue.

\section{Shortness of breath and cough}

The European Organization for Research and Treatment of Cancer Quality-of-Life Questionnaire - Lung Cancer Module (EORTC QLQ-LC13) ${ }^{28}$ was used to measure shortness of breath and cough. Patients were asked to rate their severity on each shortness of breath and cough item using a 4-point Likert scale where $1=$ not at all; $2=$ a little; 3=quite a bit; and 4=very much. The EORTC QLQ-LC13 has been validated in Norwegian patients with LC. ${ }^{29} 30$

\section{Depression}

The Center for Epidemiologic Studies - Depression Scale $(\text { CES-D })^{31}$ was used to measure depression symptoms. The scale has 20 items related to depression, and patients were asked to report how they felt during the past week. Each item was rated on a 4-point Likert scale and scores ranged from 0 to 60 , with a higher score indicating a higher level of depression. A total depression score was calculated as the mean of all the subscores. Acceptable reliability and validity have been reported in a previous study. $^{32}$

\section{Anxiety}

The State-Trait Anxiety Inventory (STAI, Y-2) ${ }^{33}$ was used to measure anxiety. The STAI includes 20 items related to anxiety rated on a 4-point Likert scale. Scores range from 20 to 80, with a higher score indicating a higher level of anxiety. The STAI has been validated in patients with LC. ${ }^{34}$

\section{Sleep disturbance}

The General Sleep Disturbance Scale (GSDS) ${ }^{35}$ was used to measure sleep disturbance. The GSDS consists of 21 items related to sleep disturbance. Each item is rated on a numeric rating scale ranging from 0 (never) to 7 (every day). A sleep disturbance score was calculated from the mean of all scale items. Higher scores indicate more severe sleep disturbance. The GSDS has been validated in patients with cancer. ${ }^{26}$

\section{Pain}

The Brief Pain Inventory (BPI) ${ }^{36}$ was used to measure pain interference. The BPI is a multidimensional questionnaire measuring pain intensity (four items), pain interference (seven items), pain relief (one item) and pain location (body map). Only pain interference was used in the present study. The seven interference items (general activity, normal work, walking ability, mood, relationships with other people, sleep and enjoyment of life) were combined into a single interference item. The measurement scale ranges from 0 to 10 , with higher scores indicating more pain interfering with daily living. The BPI has been validated in Norwegian patients with cancer. $^{37}$

\section{Ethics}

Each participant received written information about the study and signed informed consent. The article complies with the STROBE guidelines. ${ }^{38}$

\section{Statistical analyses}

Descriptive statistics were used to describe the sociodemographic, clinical and treatment characteristics of the patient sample. Differences between sexes were analysed using a $\chi^{2}$ test for categorical variables and an independent Student's t-test for the continuous variables. One-way analysis of variance was used to explore differences within groups on levels of preoperative and postoperative fatigue. Patients with more than $20 \%$ of missing items on the LFS were excluded from analyses. If the scales had less than $20 \%$ missing, the score were calculated from the mean of the particular patient's valid scores. The bivariate relationships between symptoms and fatigue at baseline were assessed using Pearson correlation analyses. Variables with significant correlation coefficients on bivariate analyses were included in a hierarchical linear analyses.

Two stepwise multivariate regression analyses were performed. In the first analysis, preoperative fatigue was the dependent variable. In the second analysis, postoperative fatigue was the dependent variable. In both analyses, age and sex were entered in step 1 . Clinical variables including comorbidities, $\mathrm{FEV}_{1}$ and $\mathrm{FVC}$ were entered in step 2. Finally, the symptom variables of shortness of breath, cough, depression, anxiety, sleep disturbance and pain interference were entered in step 3. For the second regression analysis, the model also included a fourth step in which preoperative fatigue was included as an independent variable.

The entry of variables in different model steps was carried out according to theoretical and logical considerations. For all analyses, $\mathrm{p}<0.05$ was considered statistically significant. Post hoc statistical power was calculated for hierarchical multiple regression: with an effect size $\left(f^{2}\right)$ for set B (5-month follow-up) at 0.15 (medium), ${ }^{39}$ 11 predictors in set $A$ and 12 in set $B$, a probability level of 0.05 and a sample size of 196, the observed power for the addition of set $\mathrm{B}$ was $0.95 .{ }^{40}$ Data were analysed using SPSS V.24.0.

\section{RESULTS}

\section{Sample characteristics}

In total, 375 patients with presumptive primary LC were asked to participate in the study and 307 agreed to participate (figure 1). Among these, 196 patients who answered the questionnaire both preoperatively and at 5-month follow-up and had valid fatigue scores at both measurement points were included in the study. Sample characteristics are shown in table 1. Although women were younger, more women lived alone, reported higher FVC, less shortness of breath and had a higher proportion of adenocarcinoma cancer type and was more active in physiotherapy and rehabilitation than men, their level of 


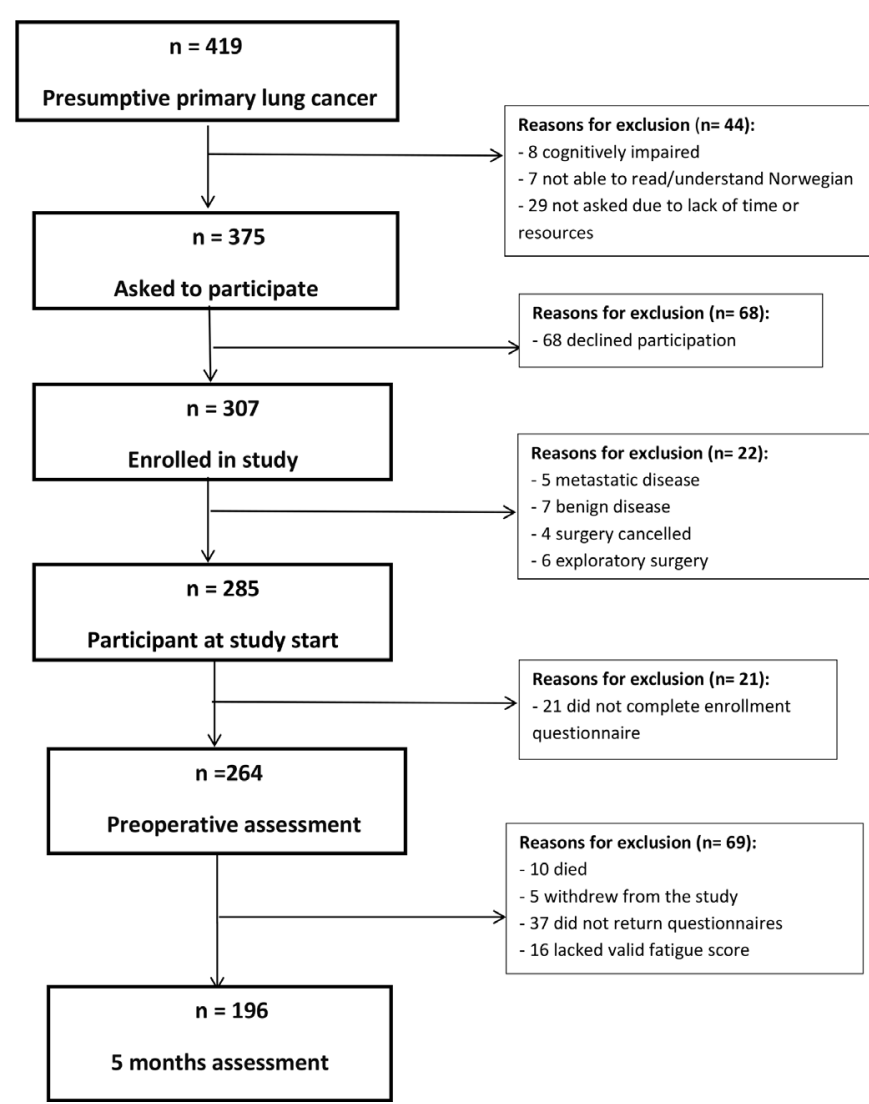

Figure 1 Flow chart of the enrolment and exclusion of patients in the study.

fatigue did not differ. Most of the sample had adenocarcinoma stage $1 \mathrm{~A}$ or $1 \mathrm{~B}$, received no preoperative treatment and had a lobectomy.

The mean preoperative fatigue scores were 2.49 $(\mathrm{SD}=2.02)$ for men and $2.47(\mathrm{SD}=1.96)$ for women. At the 5-month follow-up, the postoperative fatigue scores were $3.0(\mathrm{SD}=2.1)$ for men and $2.9(\mathrm{SD}=2.1)$ for women. There were no significant differences in fatigue level preoperatively between those who completed or did not complete the postoperative fatigue scale.

\section{Bivariate analyses}

The bivariate analyses between the symptom variables are shown in table 2. Medical and treatment characteristics including cancer stage, tumour type, type of surgery and postoperative treatment such as radiation therapy, chemotherapy, physiotherapy and rehabilitation were not significantly correlated with either preoperative or postoperative fatigue and, thus, were not included in the final model. Sociodemographic variables including work, education and cohabitation were excluded before the final analyses for the same reason.

\section{Multivariate analyses}

Hierarchical multiple regression analyses were used to assess the impact of the selected variables on levels of preoperative and postoperative fatigue (table 3). Age, sex and clinical variables were unrelated to preoperative fatigue.
At baseline, patients who reported pain scored higher on fatigue $(\mathrm{M}=2.9, \mathrm{SD}=2.05)$ compared with patients who reported no pain $(\mathrm{M}=2.03, \mathrm{SD}=1.8, \mathrm{t}=3.28, \mathrm{p}=0.001)$. Patients who reported pain at baseline also reported higher mean fatigue at 5-month follow-up (M=3.54, $\mathrm{SD}=2.21)$ compared with those who reported no pain at baseline $(\mathrm{M}=2.55, \mathrm{SD}=2.04, \mathrm{t}=3.08, \mathrm{p}=0.002)$. Among the reported symptoms, coughing, depression, sleep disturbance and pain interference were related to preoperative fatigue after controlling for age, sex, clinical variables and the other symptoms. The total model explained $46.6 \%$ of variance, while $30.5 \%$ was explained by the other symptoms.

At 5-month follow-up, the only variables that predicted fatigue after controlling for age, sex, clinical variables, preoperative fatigue and symptoms were shortness of breath and coughing. The total model explained $54.3 \%$ of variance, while $23.2 \%$ was explained by the other symptoms.

\section{DISCUSSION}

To our knowledge, this is the first study examining fatigue in surgically treated patients with LC, including both preoperative data and data from 5-month follow-up. Preoperative fatigue was significantly correlated with comorbidities and all the included symptoms in the bivariate analyses, while postoperative fatigue was significantly correlated with comorbidities and four out of six measured symptoms. However, shortness of breath was the only baseline variable that predicted postoperative fatigue.

\section{Relationship between postoperative fatigue level and preoperative symptoms}

Shortness of breath, coughing, depression, anxiety, sleep disturbance and pain interference were significantly correlated with level of preoperative fatigue. Except for anxiety and pain interference, the same symptoms were associated with postoperative fatigue in the bivariate analyses at 5-month follow-up. Before surgery, cough was significantly associated with fatigue, while shortness of breath was the symptom predictive of postoperative fatigue. Shortness of breath is a prevalent and disturbing symptom in these patients, which is physiologically based on disease location, damage caused by lung tumours and history of smoking. Shortness of breath requires intensive effort to breath, thus making patients tired. The constant use of rib and respiratory muscles caused by shortness of breath can exacerbate fatigue. ${ }^{41}$ These patients may benefit from prescribed bronchodilators and non-pharmacological treatment such as physical activity. For some, it may be useful to learn how to manage shortness of breath by controlled breathing techniques and practising calming techniques during shortness of breath episodes.

Consistent with previous research, we found that fatigue in patients with LC undergoing surgery is correlated with their symptoms and might cluster with 
Table 1 Demographic, clinical and treatment characteristics of the patients $(n=196)$

\begin{tabular}{|c|c|c|c|c|c|}
\hline & Total & Men & Women & Statistics & $P$ value \\
\hline \multicolumn{6}{|l|}{ Sociodemographics } \\
\hline \multirow[t]{2}{*}{ Age in years (mean, SD) } & 196 & $66.7(8.2)$ & $64.1(7.9)$ & t $2.28(194)$ & 0.024 \\
\hline & & $\%(n)$ & $\%(n)$ & $\chi(\mathrm{df})$ & \\
\hline Cohabitation (living with someone) & 147 & $84.0(89)$ & (69.0) 58 & $5.95(1)$ & 0.015 \\
\hline \multicolumn{6}{|l|}{ Work status } \\
\hline Full time or part time & 58 & $27.6(29)$ & $34.9(29)$ & $.80(2)$ & 0.25 \\
\hline Sick leave or disability & 47 & $22.9(24)$ & $27.7(23)$ & & \\
\hline Retired & 83 & $49.5(52)$ & $37.3(31)$ & & \\
\hline \multicolumn{6}{|l|}{ Education } \\
\hline$\leq 12$ years & 158 & $81.1(86)$ & $86.7(72)$ & $1.07(1)$ & 0.30 \\
\hline$\geq 13$ years & 31 & $18.9(20)$ & $13.3(11)$ & & \\
\hline Clinical variables & & Mean (SD) & Mean (SD) & $t(d f)$ & \\
\hline Comorbidities (SCQ) & 193 & $3.72(3.3)$ & $4.67(4.0)$ & $-1.74(161.4)$ & 0.08 \\
\hline $\mathrm{FEV}_{1}($ expected \%) & 190 & $76.7(19.2)$ & $80.4(22.8)$ & $-1.20(188)$ & 0.23 \\
\hline FVC (expected \%) & 183 & $91.2(15.00)$ & $102.4(19.4)$ & $t-4.30(149.8)$ & $<0.001$ \\
\hline \multicolumn{6}{|l|}{ Symptoms } \\
\hline Fatigue (LFS) baseline & 196 & $2.50(2.0)$ & $2.48(2.0)$ & $\mathrm{t}-0.07(194)$ & 0.94 \\
\hline Fatigue (LFS) 5 month follow-up & 196 & $3.0(2.2)$ & $2.9(2.1)$ & t 0.32 (194) & 0.75 \\
\hline $\begin{array}{l}\text { Shortness of breath } \\
\text { (EORTC) }\end{array}$ & 194 & $2.24(0.8)$ & $2.00(0.7)$ & $\mathrm{t}-2.28(192)$ & 0.023 \\
\hline Cough (EORTC) & 193 & $1.96(0.7)$ & $1.98(0.8)$ & $t-0.11(191)$ & 0.92 \\
\hline Depression (CES-D) & 190 & $10.49(8.8)$ & $12.92(8.8)$ & $\mathrm{t}-1.89(188)$ & 0.06 \\
\hline Anxiety (STAI) & 192 & $51.22(3.1)$ & $50.80(2.9)$ & t $0.96(190)$ & 0.34 \\
\hline \multirow[t]{2}{*}{ Sleep disturbance (GSDS) } & 191 & $2.26(1.05)$ & $2.32(1.00)$ & $t-0.36(189)$ & 0.72 \\
\hline & & $\%(n)$ & $\%(n)$ & $\chi(\mathrm{df})$ & $P$ value \\
\hline Pain (BPI) yes & 171 & $40.0(38)$ & $51.3(39)$ & $2.18(1)$ & 0.14 \\
\hline
\end{tabular}

Pathology and treatment

Tumour type

\begin{tabular}{|c|c|c|c|c|c|}
\hline Adenocarcinoma & 106 & $45.0(50)$ & $65.9(56)$ & $24.00(4)$ & $<0.001$ \\
\hline Squamous cell & 66 & $45.0(50)$ & $12.9(11)$ & & \\
\hline Small cell & 5 & $1.8(2)$ & $3.5(3)$ & & \\
\hline Carcinoid & 6 & $1.8(2)$ & $4.7(4)$ & & \\
\hline Other & 18 & $6.3(7)$ & $12.9(11)$ & & \\
\hline \multicolumn{6}{|c|}{ Stage of cancer disease } \\
\hline IA & 58 & $25.2(27)$ & $41.3(31)$ & $9.12(4)$ & 0.06 \\
\hline IB & 59 & $35.5(38)$ & $28.0(21)$ & & \\
\hline II & 35 & $24.3(26)$ & $12.0(9)$ & & \\
\hline IIIA & 31 & $14.0(15)$ & $18.7(14)$ & & \\
\hline IIIB-IV & 1 & $0.9(1)$ & - & & \\
\hline \multicolumn{6}{|c|}{ Preoperative treatment } \\
\hline None & 192 & $97.3(108)$ & 98.8 (84) & $1.58(3)$ & 0.66 \\
\hline Radiation & 1 & $0.9(1)$ & - & & \\
\hline Chemotherapy & 1 & $0.9(1)$ & - & & \\
\hline Combination & 2 & 0.9 (1) & $1.2(1)$ & & \\
\hline
\end{tabular}

Type of surgery 
Table 1 Continued

\begin{tabular}{lclllc}
\hline & Total & Men & Women & Statistics & P value \\
\hline Lobectomy & 133 & $67.6(75)$ & $68.2(58)$ & $1.26(4)$ & 0.87 \\
Bilobectomy & 15 & $6.3(7)$ & $9.4(8)$ & & \\
Pneumonectomy & 18 & $9.0(10)$ & $9.4(8)$ & & \\
Wedge resection & 18 & $9.9(11)$ & $8.2(7)$ & & \\
$\quad$ Thoracoscopic & 12 & $7.2(8)$ & $4.7(4)$ & & \\
Postoperative complications & & & & & 0.45 \\
$\quad$ Reoperation & 9 & $3.6(4)$ & $5.9(5)$ & $0.57(1)$ & 0.61 \\
$\quad$ Pneumonia & 50 & $27(30)$ & $23.8(20)$ & $0.26(1)$ & 0.31 \\
Post-treatment & 16 & $9.9(11)$ & $5.9(5)$ & $1.04(1)$ & 0.59 \\
$\quad$ Radiation therapy & 57 & $30.6(34)$ & $27.1(23)$ & $0.30(1)$ & $\mathbf{0 . 0 4}$ \\
$\quad$ Chemotherapy & 58 & $24.3(26)$ & $38.1(32)$ & $4.24(1)$ & $\mathbf{0 . 0 1 5}$ \\
$\quad$ Physiotherapy & 24 & $7.5(8)$ & $19.3(16)$ & $5.90(1)$ & \\
$\quad$ Rehabilitation & & & & \\
\hline
\end{tabular}

Fatigue: range $0-10$, higher score indicating greater fatigue severity; shortness of breath and cough: range 1-4, higher score indicating more shortness of breath and cough; depression: range 0-60, higher score indicating more depression; pain: range 0-10, higher score indicating more pain; comorbidity: range $0-57$, higher score indicating more comorbidity; anxiety: range $20-80$, higher score indicating more anxiety; sleep disturbance: range $0-7$, higher score indicating more severe sleep disturbance.

Bold numbers represent significant relationships.

BPI, Brief Pain Inventory; CES-D, Center for Epidemiologic Studies - Depression Scale; EORTC, European Organization for Research and Treatment of Cancer; FEV , forced expiratory volume in $1 \mathrm{~s}$; FVC, forced vital capacity; GSDS, General Sleep Disturbance Scale; LFS, Lee Fatigue Inventory; SCQ, Self-administered Comorbidity Questionnaire; STAI, State-Trait Anxiety Inventory.

other symptoms. ${ }^{2}{ }^{42}$ Cheville $e t a l^{2}$ found a cluster of fatigue, cough and dyspnoea in LC survivors lasting for 8 years; however, in a later study, the same group found that the cluster did not predict patient outcomes but that fatigue and dyspnoea, alone and together, were sufficient to predict important outcomes. ${ }^{8}$

Table 2 Correlation matrix for symptoms at baseline and fatigue baseline and 5-month follow-up ( $n=196)$

\begin{tabular}{|c|c|c|c|c|c|c|c|c|c|c|c|c|c|}
\hline & 1 & 2 & 3 & 4 & 5 & 6 & 7 & 8 & 9 & 10 & 11 & 12 & 13 \\
\hline $1 \mathrm{Age}$ & 1 & & & & & & & & & & & & \\
\hline $2 \operatorname{Sex}$ & $-0.16^{\star}$ & 1 & & & & & & & & & & & \\
\hline $4 \mathrm{FVC}$ & 0.02 & $0.31^{*}$ & $0.65^{\star}$ & 1 & & & & & & & & & \\
\hline $\begin{array}{l}5 \text { Fatigue (LFS) } \\
\text { baseline }\end{array}$ & $-0.23^{\star}$ & -0.01 & $-0.19^{\star}$ & -0.14 & 1 & & & & & & & & \\
\hline 7 Comorbidities (SCQ) & 0.04 & 0.13 & $-0.23^{*}$ & -0.12 & $0.29^{*}$ & $0.31^{*}$ & 1 & & & & & & \\
\hline $\begin{array}{l}8 \text { Shortness of breath } \\
\text { (EORTC) }\end{array}$ & -0.03 & $-0.16^{\star}$ & $-0.25^{\star}$ & $-0.24^{*}$ & $0.35^{\star}$ & $0.62^{*}$ & $0.31^{*}$ & 1 & & & & & \\
\hline 9 Cough (EORTC) & -0.04 & 0.01 & -0.14 & $-0.15^{*}$ & $0.33^{*}$ & $0.33^{*}$ & -0.04 & $0.17^{\star}$ & 1 & & & & \\
\hline 13 Pain (BPI) & 0.1 & -0.11 & 0.09 & 0.1 & $-0.25^{\star}$ & $-0.23^{\star}$ & $-0.18^{*}$ & -0.15 & -0.02 & -0.08 & $0.18^{*}$ & $-0.23^{*}$ & 1 \\
\hline
\end{tabular}

${ }^{*}$ Correlation is significant at the 0.05 level (two tailed).

BPI, Brief Pain Inventory; CES-D, Center for Epidemiologic Studies - Depression Scale; EORTC, European Organization for Research and Treatment of Cancer; FEV , forced expiratory volume in $1 \mathrm{~s}$; FVC, forced vital capacity; GSDS, General Sleep Disturbance Scale; LFS, Lee Fatigue Inventory; SCQ, Self-administered Comorbidity Questionnaire; STAI, State-Trait Anxiety Inventory. 
Table 3 Results from the two hierarchical multivariate linear regression analyses with preoperative fatigue and postoperative fatigue (at 5-month follow-up) were used as dependent variables $(n=196)$

\begin{tabular}{|c|c|c|c|c|c|c|}
\hline & \multicolumn{3}{|c|}{ Preoperative fatigue } & \multicolumn{3}{|c|}{ Postoperative fatigue } \\
\hline & Beta & $\boldsymbol{\beta}$ & P value & Beta & $\boldsymbol{\beta}$ & P value \\
\hline \multicolumn{7}{|l|}{ Sociodemographics } \\
\hline Sex & -0.39 & -0.10 & 0.16 & 0.03 & 0.01 & 0.93 \\
\hline Explained variance $\left(\mathrm{R}^{2}\right)$ & & $5.5 \%$ & 0.01 & & $2.9 \%$ & 0.10 \\
\hline $\mathrm{FEV}_{1}$ & -0.00 & -0.05 & 0.63 & -0.00 & -0.03 & 0.71 \\
\hline FVC & -0.01 & 0.04 & 0.61 & 0.00 & 0.04 & 0.65 \\
\hline Comorbidity & 0.10 & 0.18 & 0.008 & 0.05 & 0.08 & 0.19 \\
\hline $\mathrm{R}^{2}$ change & & $10.6 \%$ & $<0.001$ & & $12.1 \%$ & $<0.001$ \\
\hline Explained variance & & 16.1 & & & 15.0 & \\
\hline $\mathrm{R}^{2}$ change & & & & & $16.2 \%$ & $<0.001$ \\
\hline Explained variance & & & & & $31.2 \%$ & \\
\hline \multicolumn{7}{|c|}{ Other symptoms at baseline } \\
\hline Shortness of breath & 0.33 & 0.13 & 0.06 & 1.27 & 0.46 & $<0.001$ \\
\hline Cough & 0.64 & 0.25 & $<0.001$ & 0.50 & 0.18 & 0.004 \\
\hline Depression & 0.05 & 0.23 & 0.003 & 0.01 & 0.04 & 0.63 \\
\hline Anxiety & -0.05 & -0.07 & 0.29 & 0.00 & 0.00 & 0.95 \\
\hline Sleep disturbance & 0.02 & 0.20 & 0.01 & 0.01 & 0.11 & 0.12 \\
\hline Pain & 0.44 & 0.20 & 0.01 & -0.29 & -0.07 & 0.26 \\
\hline
\end{tabular}

Bold numbers represent significant relationships.

FEV1, forced expiratory volume in $1 \mathrm{~s}$; FVC, forced vital capacity.

Relationship between fatigue and patients' disease characteristics and treatment

Although comorbidities did not predict postoperative fatigue in our analyses, there was a bivariate relationship with fatigue both preoperatively and postoperatively. Others have also reported correlations between comorbidity and fatigue. ${ }^{6} 12$ Respiratory comorbidities and cardiac disease are especially related to fatigue in patients with LC. ${ }^{3}{ }^{43}$ We also found a correlation between fatigue and spirometry results, with lower $\mathrm{FEV}_{1}$ and $\mathrm{FVC}$ related to higher levels of fatigue at both measurement times. These variables were related to comorbidity and are an important factor in identifying and screening patients at risk for developing fatigue. Poorer respiratory test outcomes could indicate shortness of breath or respiratory comorbidities, such as COPD, and may lead to distress and exhaustion and contribute to fatigue in these patients.

Surgery type has been established as a predictor of fatigue in LC survivors, and surgery has been associated with a greater symptom burden generally. ${ }^{21}$ In the present study, treatment and disease variables did not correlate with postoperative fatigue at 5-month follow-up. These findings are inconsistent with other reports in which correlations have been found between fatigue and chemotherapy, ${ }^{9}$ and radiotherapy. ${ }^{11}$ However, our findings are consistent with those from a general cancer population on the symptom cluster of pain, fatigue, sleep disturbance and depression. That group found that symptom experiences were independent of demographic, disease or treatment effects; their findings suggest that different subgroups of patients may harbour different determinants (eg, genetic) for experiencing symptoms and suggested aetiology that are independent of demographic, disease or treatment characteristics. ${ }^{44}$

\section{Limitations}

Some study limitations need to be acknowledged. There was a 5-month gap between the two measurement points. During this time, other factors might have influenced patients' fatigue experience. Surgery type might also be a predictor of patient fatigue. ${ }^{21}$ In this study, only $6 \%$ 
of patients had video-assisted thoracoscopy; thus, it is not possible to determine whether this influenced postoperative fatigue. Detailed information on symptom management interventions such as physiotherapy and rehabilitation was not collected. However, even if these variables had been included, no detailed information about the type and length of these therapies was available.

\section{CONCLUSIONS}

Based on the findings in the present study, patients should be screened for symptoms before surgery and offered treatment for their symptoms to reduce preoperative and postoperative fatigue. Special attention should be given to treating patients' shortness of breath, since this is a modifiable predictor for which treatments are available. Further research should pay specific attention to the pair of symptoms of shortness of breath and fatigue and to the effects on fatigue and QOL when shortness of breath is treated.

\section{Author affiliations}

${ }^{1}$ Institute of Health and Society, Faculty of Medicine, University of Oslo, Oslo, Norway

${ }^{2}$ Lovisenberg Diakonale Hogskole, Oslo, Norway

${ }^{3}$ Department of Interdisciplinary Health Sciences, Institute of Health and Society, University of Oslo, Oslo, Norway

${ }^{4}$ Department of Research, Lovisenberg Diakonale Hospital, Oslo, Norway ${ }^{5}$ Institute of Health and Society, Faculty of Medicine, University of Oslo, Oslo, Norway

${ }^{6}$ Department of Research and Development, Division of Emergencies and Critical Care, Oslo universitetssykehus Ulleval, Oslo, Norway

${ }^{7}$ Faculty of Health Studies, Campus Haraldsplass, VID Vitenskapelige Hogskole, Bergen, Norway

Acknowledgements We would like to thank all of the patients who kindly participated and the nurses and physicians at Oslo University Hospital, St. Olav University Hospital and Haukeland University Hospital who facilitated data collection.

Contributors TR and TO conceptualised the study. TO wrote the protocol manuscript, and TR contributed to protocol development. TO had responsibility for data collection. TH and AL conducted the data analyses and drafted the initial report. TO and TR critically reviewed and edited the manuscript. All authors read and approved the final manuscript. Each author contributed to interpreting the analyses and to critically revising the article and approved the final draft.

Funding The study was funded by the Norwegian Cancer Association.

Competing interests None declared.

Patient consent for publication Not required.

Ethics approval The Regional Ethics Committee for the South-East 2010/1508 and the Institutional Review Boards (Personvernombudet) at each hospital approved the study.

Provenance and peer review Not commissioned; externally peer reviewed.

Data availability statement All data relevant to the study are included in the article or uploaded as supplementary information.

Open access This is an open access article distributed in accordance with the Creative Commons Attribution Non Commercial (CC BY-NC 4.0) license, which permits others to distribute, remix, adapt, build upon this work non-commercially, and license their derivative works on different terms, provided the original work is properly cited, appropriate credit is given, any changes made indicated, and the use is non-commercial. See: http://creativecommons.org/licenses/by-nc/4.0/.

\section{ORCID iD}

Anners Lerdal http://orcid.org/0000-0002-7144-5096

\section{REFERENCES}

1. Kreftregisteret. Available: https://www.kreftregisteret.no/en/General/ Publications/Cancer-in-Norway/cancer-in-norway-2017/ [Accessed 10 May 2019].

2. Cheville AL, Novotny PJ, Sloan JA, et al. Fatigue, dyspnea, and cough comprise a persistent symptom cluster up to five years after diagnosis with lung cancer. $J$ Pain Symptom Manage 2011;42:202-12.

3. Hung R, Krebs P, Coups EJ, et al. Fatigue and functional impairment in early-stage non-small cell lung cancer survivors. J Pain Symptom Manage 2011;41:426-35.

4. Portenoy RK, Itri LM. Cancer-Related fatigue: guidelines for evaluation and management. Oncologist 1999;4:1-10.

5. Lee KA, Hicks G, Nino-Murcia G. Validity and reliability of a scale to assess fatigue. Psychiatry Res 1991;36:291-8.

6. Carnio S, Di Stefano R, Novello S. Fatigue in lung cancer patients: symptom burden and management of challenges. LCTT 2016;7:73-82.

7. Sarna L, Padilla G, Holmes C, et al. Quality of life of longterm survivors of non-small-cell lung cancer. J. Clin Oncol 2002;20:2920-9.

8. Cheville AL, Novotny PJ, Sloan JA, et al. The value of a symptom cluster of fatigue, dyspnea, and cough in predicting clinical outcomes in lung cancer survivors. J Pain Symptom Manage 2011;42:213-21.

9. Long NH, Thanasilp S, Thato R. A causal model for fatigue in lung cancer patients receiving chemotherapy. Eur J Oncol Nurs 2016;21:242-7.

10. Molassiotis A, Lowe M, Blackhall F, et al. A qualitative exploration of a respiratory distress symptom cluster in lung cancer: cough, breathlessness and fatigue. Lung Cancer 2011;71:94-102.

11. Ozturk A, Sarihan S, Ercan I, et al. Evaluating quality of life and pulmonary function of long-term survivors of non-small cell lung cancer treated with radical or postoperative radiotherapy. Am J Clin Oncol 2009;32:65-72.

12. Sarna L, Cooley ME, Brown JK, et al. Symptom severity 1 to 4 months after thoracotomy for lung cancer. Am J Crit Care 2008;17:455-67.

13. Poghosyan H, Sheldon LK, Leveille SG, et al. Health-related quality of life after surgical treatment in patients with non-small cell lung cancer: a systematic review. Lung Cancer 2013;81:11-26.

14. Hoffman AJ, Given BA, von Eye A, et al. Relationships among pain, fatigue, insomnia, and gender in persons with lung cancer. Oncol Nurs Forum 2007;34:785-92.

15. Wright F, D'Eramo Melkus G, Hammer M, et al. Trajectories of evening fatigue in oncology outpatients receiving chemotherapy. $J$ Pain Symptom Manage 2015;50:163-75.

16. Wright F, D'Eramo Melkus G, Hammer M, et al. Predictors and trajectories of morning fatigue are distinct from evening fatigue. $J$ Pain Symptom Manage 2015;50:176-89.

17. Storey DJ, Waters RA, Hibberd CJ, et al. Clinically relevant fatigue in cancer outpatients: the Edinburgh cancer centre symptom study. Ann Oncol 2007;18:1861-9.

18. Huang $X$, Zhou W, Zhang Y. Features of fatigue in patients with earlystage non-small cell lung cancer. J Res Med Sci 2015;20:268-72.

19. Lerdal A, Wahl A, Rustøen T, et al. Fatigue in the general population: a translation and test of the psychometric properties of the Norwegian version of the fatigue severity scale. Scand J Public Health 2005;33:123-30.

20. Loge JH, Ekeberg O, Kaasa S. Fatigue in the general Norwegian population: normative data and associations. J Psychosom Res 1998;45:53-65.

21. Yang P, Cheville AL, Wampfler JA, et al. Quality of life and symptom burden among long-term lung cancer survivors. J Thorac Oncol 2012;7:64-70.

22. Oksholm T, Rustoen T, Cooper B, et al. Trajectories of symptom occurrence and severity from before through five months after lung cancer surgery. J Pain Symptom Manage 2015;49:995-1015.

23. Oksholm T, Miaskowski C, Solberg S, et al. Changes in symptom occurrence and severity before and after lung cancer surgery. Cancer Nurs 2015;38:351-7.

24. Oksholm T, Miaskowski C, Kongerud JS, et al. Does age influence the symptom experience of lung cancer patients prior to surgery? Lung Cancer 2013;82:156-61.

25. Sangha O, Stucki G, Liang MH, et al. The self-administered comorbidity questionnaire: a new method to assess comorbidity for clinical and health services research. Arthritis Rheum 2003;49:156-63.

26. Miaskowski C, Lee KA. Pain, fatigue, and sleep disturbances in oncology outpatients receiving radiation therapy for bone metastasis: a pilot study. J Pain Symptom Manage 1999;17:320-32. 
27. Lerdal A, Kottorp A, Gay CL, et al. Lee fatigue and energy scales: exploring aspects of validity in a sample of women with HIV using an application of a Rasch model. Psychiatry Res 2013;205:241-6.

28. Bergman B, Aaronson NK, Ahmedzai S, et al. The EORTC QLQLC13: a modular supplement to the EORTC core quality of life questionnaire (QLQ-C30) for use in lung cancer clinical trials. Eur J Cancer 1994;30:635-42.

29. Giesinger JM, Kieffer JM, Fayers PM, et al. Replication and validation of higher order models demonstrated that a summary score for the EORTC QLQ-C30 is robust. J Clin Epidemiol 2016;69:79-88.

30. Michelson $\mathrm{H}$, Bolund $\mathrm{C}$, Nilsson $\mathrm{B}$, et al. Health-related quality of life measured by the EORTC QLQ-C30--reference values from a large sample of Swedish population. Acta Oncol 2000;39:477-84.

31. Radloff LS. The CES-D scale: a self-report depression scale for the general population. Appl Psych Mea 1977;1:385-401.

32. Sheehan TJ, Fifield J, Reisine S, et al. The measurement structure of the center for epidemiologic studies depression scale. J Pers Assess 1995;64:507-21.

33. Spielberger CD, Gorsuch RC, Lushene RE, et al. Manual for the State-Trait anxiety inventory (form Y): Self-Evaluation questionnaire. Palo Alto, CA: Consulting Psychologists Press, 1983.

34. Cataldo JK, Brodsky JL. Lung cancer stigma, anxiety, depression and symptom severity. Oncology 2013;85:33-40.

35. Lee KA. Self-Reported sleep disturbances in employed women Sleep 1992;15:493-8.
36. Cleeland CS. Measurement and prevalence of pain in cancer. Semin Oncol Nurs 1985;1:87-92.

37. Klepstad P, Loge JH, Borchgrevink PC, et al. The Norwegian brief pain inventory questionnaire: translation and validation in cancer pain patients. J Pain Symptom Manage 2002;24:517-25.

38. von Elm E, Altman DG, Egger M, et al. Strengthening the reporting of observational studies in epidemiology (STROBE) statement: guidelines for reporting observational studies. BMJ 2007;335:806-8.

39. Cohen J. A power primer: quantitative methods in psychology. Psychological Bulletin 1992;112:155-9.

40. Soper DS. Post-hoc statistical power calculator for hierarchical multiple regression (software), 2017. Available: http://www. danielsoper.com/statcalc/references.aspx?id=17 [Accessed 10 May 2019].

41. Esper P, Heidrich D. Symptom clusters in advanced illness. Semin Oncol Nurs 2005;21:20-8.

42. Lin S, Chen Y, Yang L, et al. Pain, fatigue, disturbed sleep and distress comprised a symptom cluster that related to quality of life and functional status of lung cancer surgery patients. J Clin Nurs 2013;22:1281-90.

43. Yun YH, Kim YA, Min YH, et al. Health-Related quality of life in disease-free survivors of surgically treated lung cancer compared with the general population. Ann Surg 2012;255:1000-7.

44. Miaskowski C, Cooper BA, Paul SM, et al. Subgroups of patients with cancer with different symptom experiences and quality-of-life outcomes: a cluster analysis. Oncol Nurs Forum 2006;33:E79-E89. 